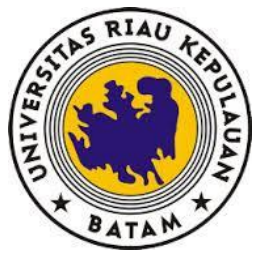

Available online at www.journal.unrika.ac.id

Jurnal KOPASTA

Jurnal KOPASTA, 6(1), (2019) 1-12

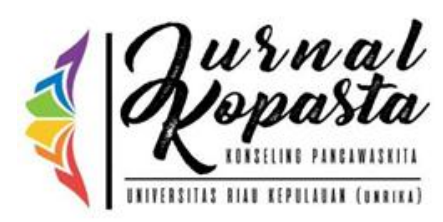

\title{
MENGURANGI AGRESI VERBAL SISWA MELALUI TEKNIK SOSIODRAMA (Studi Eskperimen kelas VII MTs Islamic Center Nahdlatul Wathan Batam)
}

\author{
REDUCING STUDENT VERBAL AGGRESSION THROUGH SOSIODRAMA TECHNIQUES \\ (Experiments for class VII of the MTs Islamic Center Nahdlatul Wathan Batam)
}

\author{
Tamama Rofiqah \& Susi Yana \\ *Division of Counseling and Guidance, University, of Riau Kepulauan, Batam \\ *Email: rofiqah87@gmail.com
}

\begin{abstract}
ABSTRAK
Teknik sosiodrama merupakan pemberian bantuan kepada siswa yang memiliki permasalahan dalam hubungan sosial dengan cara membentuk sebuah kelompok dan permasalahannya akan diselesaikan dengan bermain peran. Dengan mengikuti teknik sosiodrama ini siswa diharapkan dapat meningkatkan keterampilan dalam bertingkah laku dan bersosial. Penelitian ini bertujuan untuk mengetahui apakah teknik sosiodrama dapat mengurangi perilaku agresi verbal siswa. Jenis penelitian ini adalah penelitian eksperimen dengan rancangan PreEskperimen ( The One Group Pretest-Posttest Design). Penelitian dilakukan di MTs Islamic Center Nahdlatul Wathan dengan sampel penelitian sebanyak 20 orang. Instrument yang digunakan adalah angket skala likert. Data dianalisis dengan menggunakan rumus Wilcoxon Signed Rank Test. Temuan penelitian menunjukkan bahwa secara umum perilaku agresi verbal siswa dapat dikurangi melalui penerapan teknik sosiodrama. Oleh karena itu, salah satu cara yang dapat digunakan oleh guru BK dalam menangani siswa yang berperilaku agresi adalah dengan menerapkan teknik sosiodrama.
\end{abstract}

\section{Kata Kunci: Teknik Sosiodrama, Agresi Verbal}

\begin{abstract}
Sociodrama technique is giving assistance to students who have problems in social relations by forming a group and the problems will be solved by playing a role. By following this sociodrama technique students are expected to be able to improve their behavior and social skills. This study aims to determine whether sociodrama techniques can reduce students' verbal aggression behavior. This type of research is an experimental study with the design of Pre-Experimental (The One Group Pretest-Posttest Design). The study was conducted at the Nahdlatul Wathan MTs Islamic Center with a sample of 20 people. The instrument used is a Likert scale questionnaire. Data were analyzed using the Wilcoxon Signed Rank Test formula. The research findings show that in general students' verbal aggression behavior can be reduced through the application of sociodrama techniques. Therefore, one way that can be used by counselors in handling students who behave aggressively is to apply sociodrama techniques.
\end{abstract}

Keywords: Sociodrama Technique, Verbal Aggression

\section{PENDAHULUAN}

Masa remaja merupakan masa perkembangan transisi antara masa kanak-kanak menuju masa dewasa, yang dimulai dari masa pubertas, dan ditandai dengan adanya perubahan yang pesat dalam berbagai aspek perkembangan. Berbagai perubahan yang terjadi seringkali menimbulkan kebingungan di kalangan remaja sehingga memunculkan sikap, perilaku, 
kesehatan serta kepribadian remaja yang tidak harmonis. Erikson (2011) mengemukakan bahwa terdapat beberapa macam bahaya pada masa remaja, yaitu : (1) tidak bertanggung jawab, menyepelekan tugas-tugas sekolah dengan lebih memilih bersenang-senang dan mendapat dukungan sosial, (2) sikap yang terlalu percaya diri dan agresif, (3) perasaan tidak aman, sehingga remaja cenderung patuh terhadap kelompoknya, (4) merasa ingin pulang jika jika berada pada lingkungan yang tidak dikenal, (5) perasaan menyerah, (6) terlalu banyak berkhayal, (7) mundur ketingkatan perilaku sebelumnya untuk menarik perhatian, (8) menggunakan mekanisme pertahanan ego: rasionalisasi, proyeksi, berkhayal dan memindahkan. Dan salah satu yang terjadi pada masa ini adalah perilaku agresif. Borkowitz (2003) mendefinisikan agresif adalah segala bentuk perilaku yang dimaksudkan untuk menyakiti seseorang baik secara fisik maupun mental. Sedangkan Krech (dalam Zamzani, 2007), agresif adalah berupa kata-kata seperti pengaduan dan fitnah serta fantasi kekerasan dan penyerbuan.

Berkaitan dengan perilaku agresif remaja tersebut, Laela Siddiqah (2010) menunjukkan data kepolisian kota Yogyakarta pada tahun 2008 terdapat 78 kasus agresif remaja, dan telah diproses secara hukum pada tahun 2003 hingga 2006 dengan pelanggaran berupa penggunaan senjata tajam, penganiayaan, pengeroyokan, pencabulan, pemerkosaan, termasuk pencurian dan penggelapan rentang usia pelaku berkisar antara usia 16-18 tahun. Selanjutnya, hasil penelitian Satria, AR, dkk (2015) tentang hubungan kecanduan bermain video games kekerasan dengan perilaku agresif pada siswa laki-laki kelas IV dan V di SD 02 Cupak Tengah Pauh kota Padang, mengemukakan bahwa kecanduan video games yang mengandung unsur kekerasan memiliki perilaku agresif lebih tinggi dengan persentase 67,6\%:20,4\%.

Jonathan N. Onukwofur (2013) dalam penelitiannya tentang perbedaan prevalensi jenis kelamin dan tingkat pendidikan perbedaan dalam agresi fisik dan verbal siswa remaja sekolah menengah memaparkan bahwa 20,8\% siswa sekolah menengah yang melakukan agresi fisik, sedangkan prevalensi agresi verbal antar siswa 48,3\%. Prevalensi agresi fisik dan verbal lebih tinggi diantara laki-laki daripada perempuan. Ada perbedaan yang signifikan tentang agresi fisik antara laki-laki dan perempuan.

Penerapan konseling behavioral dengan teknik pengondisian operan untuk menurunkan perilaku agresif siswa yang dilakukan oleh Adnyani, A. dkk, mengemukakan bahwa diperoleh rata-rata pencapaian perilaku agresif terhadap 7 orang siswa sebesar 63,50\% dengan kategori tinggi. Pada siklus I terjadi peningkatan dengan rata-rata $11,11 \%$ dengan hasil 5 orang siswa dengan kategori sedang dan 2 orang siswa kategori tinggi, sehingga perlu dilanjutkan dengan siklus II. Hasil yang diperoleh pada siklus II menunjukkan bahwa siswa 
berada pada kategori rendah dengan rata-rata $18,57 \%$, hal ini menunjukkan bahwa perilaku agresif siswa dapat diatasi dengan teknik pengondisian operan. Data ini juga diperkuat oleh hasil pengamatan perilaku agresif yang diisi oleh peneliti setiap pertemuan. Hal ini menunjukkan bahwa pentingnya peran sekolah, guru dan guru BK untuk dapat membimbing siswa agar tidak berperilaku agresif.

Pada realitanya, berdasarkan hasil wawancara dengan guru BK di MTs Islamic Center Nahdlatul Wathan, diperoleh data bahwa ada siswa yang berperilaku agresif seperti berkata kasar terhadap temannya, menghina, mengejek, memukul dan melukai perasaan teman. Perilaku ini juga ditunjukkan oleh siswa terhadap guru di sekolah seperti menentang perintah guru. Selanjutnya berkaitan dengan pelayanan BK di sekolah, diperoleh data bahwa pelaksanaan BK belum optimal dikarenakan latar belakang guru BK bukan dari sarjana BK. Sehingga pelaksanaan BK yang seharusnya belum dapat dirasakan oleh siswa di sekolah.

Berdasarkan data tersebut di atas, maka peneliti ingin mengkaji dan mendalami permasalahan agresif siswa dengan menerapkan teknik sosiodrama. Romlah (dalam Lilis Erma Suryani, 2001) sosiodrama adalah permainan peranan yang ditunjukkan untuk memecahkan masalah sosial yang timbul dalam hubungan sosial antar manusia. Tujuannya agar siswa berani mengungkapkan pendapat secara lisan, memupuk kerjasama antara siswa, siswa menjiwai tokoh yang diperankan serta melatih cara berinteraksi dengan orang lain. Oleh karena itu, penerapan teknik sosiodrama ini diduga dapat menurunkan perilaku agresif pada siswa. Adapun rumusan masalah dalam penelitian ini berupa :

1. Bagaimana perilaku agresif siswa sebelum diberikan teknik sosiodrama?

2. Bagaimana perilaku agresif siswa setelah diberikan teknik sosiodrama ?

3. Apakah teknik sosiodrama dapat mengurangi perilaku agresif siswa ?

Berdasarkan rumusan masalah tersebut, maka yang menjadi tujuan dari penelitian ini adalah mengetahui dan mendeskripsikan perilaku agresif siswa sebelum dan sesudah diberikannya teknik sosiodrama, serta mengetahui apakah teknik sosiodrama dapat mengurangi perilaku agresif siswa.

\section{LANDASAN TEORI}

\section{Perilaku Agresif}

Myers (2002) menjelaskan bahwa perilaku agresif adalah perilaku fisik atau lisan yang sengaja dengan maksud untuk menyakiti atau merugikan orang lain. Murray (dalam Chaplin, 2004) mengemukakan bahwa agresif adalah kebutuhan untuk menyerang, memperkosa atau melukai orang lain, untuk meremehkan, merugikan, mengganggu, membahayakan, merusak, 
menjahati, mengejek, mencemooh atau menuduh secara jahat, menghukum berat atau melakukan tindakan sadistis lainnya. Selanjutnya, istilah agresi erat hubungannya dengan kemarahan, Navaco dan Borkowitz (dalam Azmi, 2015) menyebutkan kemarahan bisa terjadi karena tidak mendapatkan apa yang diinginkan. Sedangkan Anderson dan Huesmann (2003) mengatakan bahwa "behavior directed towards another individual carried out with the proximate (immediate) intent to cause harm", perilaku agresif adalah perilaku yang diarahkan kepada individu lain dengan proksimat (langsung) dengan niat untuk menyakiti.

Adapun bentuk perilaku agresif dapat dibagi menjadi dua yaitu agresif fisik dan agresif verbal (Sameer dan Jamia dalam Onukwofur, 2013) yaitu : (1) agesif fisik adalah bentuk agresi yang memusuhi dengan tujuan untuk menyebabkan kerusakan tubuh. Contohnya menendang, menganiaya, mendorong, menyiksa, berkelahi, intimidasi, menusuk, menembak dan sebagainya, sedangkan (2) agresif verbal meliputi tindakan seperti menghina dengan bahasa yang buruk, menampilkan kemarahan, mengancam, bersumpah dan suka menyindir semua untuk menyebabkan rasa sakit emosional dan psikologis.

Bandura (dalam Alwisol, 2006) mengemukakan faktor-faktor penyebab perilaku agresif ada dua, yakni faktor internal dan faktor eksternal. Faktor internal berhubungan dengan diri individu itu sendiri seperti inteligensi, emosi dan sebagainya, sedangkan faktor eksternal seperti kurangnya perhatian orang tua, imitasi dari pergaulan yang salah, keluarga yang broken home, adanya solidaritas antar sesame siswa, adanya konflik keluarga, perasaan tersinggung, jengkel dan sakit hati, memalak, kurangnya tanggapan orang tua terhadap perilaku siswa.

Selanjutnya, perilaku agresif dapat dicegah dengan beberapa cara. Baron (2002) menjelaskan beberapa prosedur yang dapat digunakan untuk mengendalikan perilaku agresif antara lain : (1) hukuman, yakni pemberian konsekuensi yang menyakitkan untuk mengurangi perilaku tertentu sebagai suatu teknik untuk mengurangi agresi, (2) katarsis, yaitu pandangan bahwa jika individu mengekspresikan kemarahan mereka dengan cara yang relative tidak menimbulkan bahaya, tendensi mereka untuk terlibat dalam tipe agresif yang berbahaya akan berkurang, (3) teknik lain untuk mengurangi perilaku agresif diantaranya pemaparan terhadap model non agresif, pelatihan dalam keterampilan sosial, dan respons yang tidak tepat.

\section{Teknik Sosiodrama}

Menurut Ahmadi dan Supriyono (dalam Dian, 2013) teknik sosiodrama adalah suatu cara dalam bimbingan yang memberikan kesempatan kepada siswa untuk mendramatisasikan 
sikap, tingkah laku atau penghayatan seseorang seperti yang dilakukan dalam hubungan sosial sehari-hari di masyarakat. Romlah (dalam Lilis. 2001) menyatakan bahwa sosiodrama adalah permainan peranan yang ditunjukkan untuk memecahkan masalah sosial yang timbul dalam hubungan sosial antar manusia. Sosiodrama memberikan kesempatan kepada siswa untuk berpendapat atau mencari pemecahan masalah dengan cara-cara lain kemudian di ambil kesimpulan. Sosiodrama tidak memerlukan keahlian sandiwara tetapi kepada spontan terhadap pengalaman siswa.

Wingkel (2004) mengemukakan beberapa tujuan dan manfaat sosiodrama bagi siswa diantaranya : (1) siswa berani mengungkapkan pendapat secara lisan, (2) memupuk kerjasama di antara siswa, (3) berani memerankan tokoh, (4) menjiwai tokoh yang diperankan, (5) siswa memberikan tanggapan terhadap pelaksanaan sosiodarama yang telah dilakukan, (6) melatih cara berinteraksi dengan orang lain. Engkoswara ( dalam Ulti Latifah, 2001) mengungkapkan tujuan sosiodrama yaitu meiputi : (1) untuk melatih anak mendengarkan dan menangkap cerita singkat dengan teliti, (2) memupuk dan melatih keberanian, (3) memupuk daya cipta, (4) belajar menghargai dan menilai orang lain menyatakan pendapat, (5) mendalami masalah sosial.

Prosedur pelaksanaan sosiodrama menurut Nana Sudjana (2002) meliputi kegiatan : (1) Tahap Persiapan yaitu penentuan pokok permasalahan yang akan di dramatisasikan, menentukan pemain, dan mempersiapkan para siswa sebagai pendengar yang menyaksikan jalan cerita, (2) Tahap pelaksanaan yaitu para siswa diberikan kesempatan untuk menggambarkan, mengungkapkan dan mengekspresikan sikap, tingkah laku atau penghayatan sesuatu yang dipikirkan, dirasakan atau diinginkan seandainya ia menjadi tokoh yang diperankan, (3) Tahap tindak lanjut yaitu tahapan setelah berakhirnya sosiodrama seperti Tanya jawab, diskusi, kritik dan analisis persoalan. Adapun tema sosiodrama yang diberikan untuk mengurangi perilaku agresif siswa pada penelitian ini adalah : menghina teman, marah tanpa alasan, pentingnya menjaga lisan dan akibat suka membantah. 


\section{Kerangka berpikir}

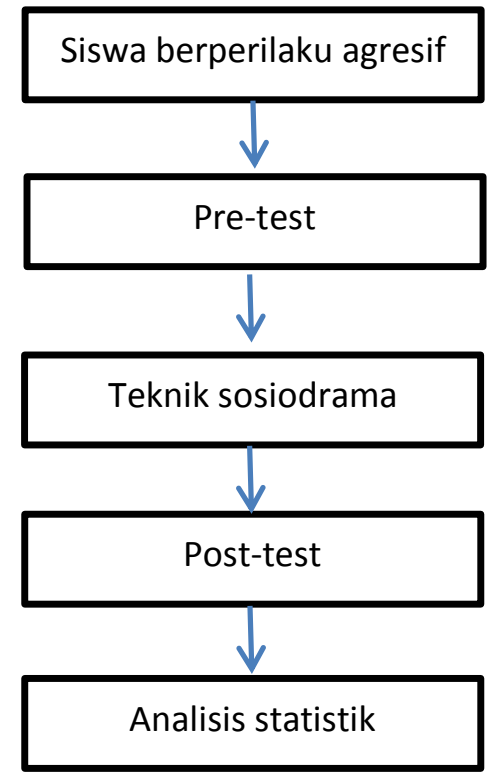

Gambar 1. Kerangka berpikir

\section{Hipotesis}

Ha $\quad$ : Teknik sosiodrama dapat mengurangi perilaku agresif siswa

Ho $\quad$ : Teknik sosiodrama tidak dapat mengurangi perilaku agresif siswa

\section{METODOLOGI}

Jenis penelitian ini merupakan Pre-Eskperimen Design dengan menggunakan One-grup pretest-posttest design (Sugiyono, 2013). Dalam penelitian ini sampel tidak dipilih secara random. Penelitian ini menggunakan pretest sebelum diberi perlakuan dan posttest setelah diberi perlakuan, design ini dapat dilihat pada gambar berikut :

\section{$01 \times 02$}

Gambar 2. Design penelitian

Keterangan :

O1 : Skor pretest ( sebelum diberi perlakuan)

O2 : Skor posttest ( setelah diberi perlakuan)

$\mathrm{X} \quad$ : Treatment (perlakuan) yang diberikan 
Populasi dalam penelitian ini adalah seluruh siswa kelas VII MTs Islamic Center Nahdlatul Wathan Batam yang berjumlah 20 orang. Pengambilan sampel dilakukan dengan teknik purposif sampling dengan kriteria sebagai berikut :

1. Siswa yang membantah perintah guru

2. Siswa yang berkata kasar dan tidak sopan terhadap guru maupun teman

3. Siswa yang saling mengejek, mencemooh teman sebaya

4. Berdasarkan hasil pretest

Berdasarkan kriteria di atas, diperoleh sampel penelitian sebanyak 12 orang.

Definisi operasional dalam penelitian ini adalah, yang dimaksud dengan agresi verbal yaitu tindakan yang dilakukan individu secara langsung dengan cara mengejek, berkata kasar, menampilkan kemarahan, membantah, bersumpah dan menyindir untuk menimbulkan rasa sakit emosional dan psikologis pada orang lain. Sedangkan teknik sosiodrama yaitu siswa memerankan sebuah drama dan menjadi pemeran dalam drama tersebut.

Instrument penelitian yang digunakan adalah angket dengan model skala likert. Skala likert digunakan untuk mengukur sikap, pendapat dan persepsi seseorang atau sekelompok orang tentang fenomena sosial (Sugiyono, 2013). Pengujian validitas instrument menggunakan validitas konstruk. Sedangkan untuk reabilitas instrument menggunakan rumus Alpha Cronbach. Kemudian data dianalisis dengan menggunakan analisis non parametric dengan teknik Wilcoxon signed ranks test.

\section{HASIL DAN PEMBAHASAN}

1. Hasil Penelitian

Hasil penelitian ini adalah untuk menjawab rumusan masalah dan hipotesis penelitian. Adapun deskripsi data hasil penelitian secara rinci sebagai berikut :

Data penelitian yang telah di olah kemudian dianalisis untuk menjawab seluruh rumusan masalah. Perilaku agresif siswa dalam penelitian ini dikategorisasi menggunakan rumus interval sebagai berikut :

$$
\mathrm{I}=\frac{\mathrm{ST}-\mathrm{SR}}{\mathrm{K}}
$$

Keterangan :

I : Interval

ST : Skor Tertinggi

SR : Skor Terendah

K : Banyak kelas 
Pada instrument penelitian terdiri dari 37 butir item dengan skala jawaban 1-4. Skor tertinggi yang diperoleh yaitu 126 dan skor terendah 86. Maka untuk menghitung intervalnya adalah :

$\mathrm{I}=(126-86): 5=40: 5=8$

Berdasarkan hasil perhitungan di atas, maka kategorisasi perilaku agresif dapat dilihat pada table di bawah ini :

\section{Table 1. Tabel Kategori Perilaku Agresif siswa}

\begin{tabular}{|c|c|}
\hline interval & kategori \\
\hline$>121$ & Sangat Tinggi \\
\hline $112-120$ & Tinggi \\
\hline $103-111$ & Sedang \\
\hline $94-102$ & Rendah \\
\hline$<93$ & Sangat Rendah \\
\hline
\end{tabular}

a. Deskripsi data tentang perilaku agresif siswa sebelum diberikan perlakuan

Pelaksanaan pretest bertujuan untuk mengetahui gambaran awal kondisi perilaku agresif siswa sebelum diberikan perlakuan teknik sosiodrama. Adapun hasil pretest dapat dilihat pada table berikut :

Table 2. Distribusi skor pretest perilaku agresif verbal siswa

\begin{tabular}{|l|l|l|l|}
\hline \multicolumn{3}{|c|}{ Pretest } \\
\hline No & Inisial & Skor & Kategori \\
\hline 1 & A & 125 & Sangat Tinggi \\
\hline 2 & D & 115 & Tinggi \\
\hline 3 & E & 102 & Sedang \\
\hline 4 & F & 123 & Sangat Tinggi \\
\hline 5 & G & 126 & Sangat Tinggi \\
\hline 6 & H & 124 & Sangat Tinggi \\
\hline 7 & K & 104 & Sedang \\
\hline 8 & L & 109 & Sedang \\
\hline 9 & M & 114 & Tinggi \\
\hline 10 & N & 107 & Sedang \\
\hline 11 & S & 105 & Sedang \\
\hline 12 & T & 120 & Sangat Tinggi \\
\hline Total skor & 1374 & \\
\hline
\end{tabular}

Berdasarkan table di atas terungkap bahwa hasil pretest tentang kondisi perilaku agresif verbal siswa yaitu terdapat 5 siswa dengan kategori sangat tinggi, 2 siswa kategori tinggi, dan 5 siswa dengan kategori sedang. Selanjutnya dilakukan teknik sosiodrama untuk mengurangi perilaku agresif verbal siswa sebanyak 4 kali. Dari data tersebut dapat disimpulkan bahwa perilaku agresif verbal siswa cenderung tinggi. 
b. Deskripsi data tentang perilaku agresif siswa setelah diberikan perlakuan

Setelah dilakukan treatment dengan pemberian teknik sosiodrama kepada siswa. Selanjutnya siswa diberikan posttest untuk melihat pengaruh dari treatment yang diberikan. Adapun deskripsi data posttest perilaku agresi verbal siswa dapat dilihat pada table di bawah ini :

Tabel 3. Distribusi skor posttest perilaku agresif verbal siswa

\begin{tabular}{|l|l|l|l|}
\hline \multicolumn{4}{|c|}{ Posttest } \\
\hline No & Inisial & Skor & Kategori \\
\hline 1 & A & 106 & Sedang \\
\hline 2 & D & 88 & Sangat rendah \\
\hline 3 & E & 100 & Rendah \\
\hline 4 & F & 90 & Sangat rendah \\
\hline 5 & G & 99 & Rendah \\
\hline 6 & H & 103 & Sedang \\
\hline 7 & K & 90 & Sangat rendah \\
\hline 8 & L & 87 & Sangat rendah \\
\hline 9 & M & 87 & Sangat rendah \\
\hline 10 & N & 80 & Sangat rendah \\
\hline 11 & S & 81 & Sangat rendah \\
\hline 12 & T & 96 & Rendah \\
\hline Total skor & 1107 & \\
\hline
\end{tabular}

Berdasarkan table di atas terungkap bahwa hasil posttest tentang kondisi perilaku agresif verbal siswa setelah diberikan perlakuan teknik sosiodrama cenderung mengalami penurunan, yaitu terdapat 7 siswa dengan kategori sangat rendah, 3 siswa kategori rendah, dan 2 siswa dengan kategori sedang.

c. Pengujian hipotesis

Pengujian hipotesis dilakukan dengan menggunakan rumus non parametric yaitu Wilcoxon signed rank test. Adapun hasil pengujian hipotesis dapat dilihat pada table berikut:

Tabel 4. Hasil analisis Wilcoxon Signed Rank Test

Test statistics ${ }^{\mathrm{a}}$

\begin{tabular}{|l|c|}
\hline & Sesudah-sebelum \\
\hline $\begin{array}{l}\text { Z Asymp. Sig. (2- } \\
\text { tailed) }\end{array}$ & $-3,072^{\mathrm{b}}$ \\
\hline
\end{tabular}

a. Wilcoxon signed rank test

b. Based on positive rank 
Berdasarkan table di atas, dapat dilihat bahwa $\mathrm{Z}$ skor untuk uji dua sisi adalah $-3,072$ dengan signifikansi 0,002. Maka Ho di tolak dan Ha diterima, hal ini dapat diartikan bahwa terdapat perbedaan perilaku agresif verbal siswa sebelum dan setelah diberikan teknik sosiodrama. Maka dapat disimpulkan bahwa teknik sosiodrama dapat mengurangi perilaku agresif siswa.

\section{Pembahasan}

Temuan penelitian mengungkapkan bahwa teknik sosiodrama dapat mengurangi perilaku agresi verbal siswa. Berdasarkan data dari perolehan skor siswa pada saat pretest atau sebelum diberikannya perlakuan teknik sosiodrama yaitu terdapat 5 orang siswa berada pada kategori sangat tinggi, 5 orang siswa pada kategori tinggi dan 2 orang siswa pada kategori sedang. Dengan perolehan skor tertinggi adalah 126 dan skor terendah 102 dengan jumlah total skor sebesar 1374. Hal ini menunjukkan bahwa kondisi perilaku agresi siswa cenderung tinggi. Menurut Myers (2002) perilaku agresi adalah suatu bentuk perilaku yang mempunyai niat tertentu untuk melukai fisik maupun psikologis pada diri orang lain. Pendapat ini menjelaskan bahwa perilaku agresi adalah perilaku yang mengganggu dan merugikan bagi orang lain sehingga keberadaannya perlu dikurangi bahkan bisa untuk dihilangkan.

Salah satu cara yang digunakan dalam penelitian ini untuk mengurangi perilaku agresi verbal siswa adalah dengan menerapkan teknik sosiodrama. Pelaksanaan teknik sosiodrama ini dilakukan dengan membentuk kelompok. Tema yang dimainkan dalam drama meliputi menghina teman, marah hobiku, pentingnya menjaga lisan dan akibat suka membantah. Dalam memerankan drama, para siswa tidak hanya membayangkan suatu kejadian melainkan ikut merasakan kejadian itu sendiri. Setelah sesi drama selesai dilanjutkan dengan kegiatan diskusi dan Tanya jawab berkaitan dengan tema yang telah diperankan. Hal ini bertujuan untuk merubah pola pikir siswa dan lambat laun mengubah pola perilakunya. Perubahan ini terlihat saat proses pengamatan berlangsung bahwa setelah dilakukannya sosiodrama, para siswa tampak lebih berhati-hati dalam berbicara.

Keberhasilan teknik sosiodrama dalam mengurangi perilaku agresi verbal siswa terlihat dari perolehan skor posttest yaitu terdapat 7 siswa dengan kategori sangat rendah, 3 siswa kategori rendah, dan 2 siswa dengan kategori sedang. Dengan perolehan skor tertinggi sebesar 103 dan skor terendah sebesar 80 dengan jumlah total skor sebesar 1107. Hal ini juga terlihat dari hasil mean dari pretest sebesar 114,50 dan posttest sebesar 92,25. Data ini juga diperkuat dengan hasil uji hipotesis yang menunjukkan bahwa nilai $\mathrm{Z}$ skor adalah $-3,072$ 
dengan signifikansi 0,002. Dengan demikian dapat disimpulkan bahwa teknik sosiodrama dapat mengurangi perilaku agresi verbal pada siswa.

\section{PENUTUP}

Perilaku agresi pada dasarnya adalah tingkah laku yang dijalankan oleh individu dengan maksud melukai dan mencelakakan individu lain dengan atau tanpa tujuan tertentu. Perilaku ini dapat mengganggu dan merugikan orang lain. Perilaku agresi dalam penelitian ini adalah agresi verbal pada siswa kelas VII MTs Islamic Center Nahdlatul Wathan Batam. Kondisi perilaku agresi verbal siswa sebelum diberikan perlakuan cenderung tinggi. Hal ini berarti secara umum, agresi verbal kerap dilakukan oleh siswa. Salah satu cara yang digunakan dalam mengurangi perilaku ini yaitu dengan menerapkan teknik sosiodrama. Teknik sosiodrama yang diberikan menuntut siswa untuk memainkan peran sesuai dengan tema yang telah ditentukan. Selain memainkan peran, para siswa juga menghayati dan merasakan setiap kejadian dalam drama. Selanjutnya dilakukan Tanya jawab dan diskusi yang bertujuan menstimulasi pola pikir siswa agar mampu memahami makna dari setiap peran yang dimainkan. Kondisi perilaku agresi verbal siswa setelah diberikan teknik sosiodrama mengalami penurunan, hal ini terlihat dari perolehan skor dan rata-rata skor. Dengan demikian dapat dipahami bahwa penggunaan teknik sosiodrama bisa menjadi salah satu upaya preventif dalam mengurangi perilaku agresi verbal pada siswa.

\section{DAFTAR PUSTAKA}

Baron, R.A, \& Byrne, D. (2005). Psikologi Sosial Edisi ke-10 Jilid 2. Jakarta: Erlangga.

Berkowitz, Leonard. (2003). Emotional Behavior (Mengenali Perilaku dan Tindakan Kekerasan di Lingkungan Sekitar Kita dan Cara Penanggulangannya). Alih Bahasa: Hartanti Woro. Jakarta: PPM

Dian Muslimatun Azizah (2013). Mengurangi Perilaku Agresi Siswa Melalui Layanan Klasikal Menggunakan Teknik Sosiodrama. Indonesian Journal of Guidance and Counseling

Jonathan N. Onukwofur .(2013).Physical and Verbal Aggression Among Adolescent Secondary School Students in Rivers State of Nigeria. International Journal of Education Learning and Development. Vol 1 Nomor 2. 
Laela Siddiqah. (2010). Pendegahan dan Penanganan Perilaku Agresi Remaja Melalui Pengelolaan Amarah. Journal Psikologi. Volume 37 Nomor 1.

Lilis Erma Suryani.(2001). Penerapan Teknik Sosiodrama untuk Komunikasi yang Beretika pada Siswa di SMA Negeri 1 Gondang. Journal Bimbingan Konseling. Vol 1 Nomor 2.

Myers, David G. (2002). Social Psychologi (Psikologi Sosial). Alih Bahasa: Aliya Tusyani, dkk. Jakarta: Salemba Humanika

Nana Sudjana (2002).Dasar-dasar Proses Belajar Mengajar. Bandung : Sinar Baru Algensindo.

Sugiyono. (2013). Metode Penelitian Pendidikan Pendekatan Kuantitatif, Kualitatif, dan $R \& D$. Bandung: Alfabeta.

Ulti Latifah (2001).Penerapan Teknik Sosiodrama untuk Meningkatkan Komunikasi yang Beretika pada Siswa di SMA Negeri 1 Gondang. Jurnal BK Vol 3 nomor 1.

Wingkel (2004).Bimbingan dan Konseling di Institusi Pendidikan. Jakarta: PT Gramedia.

Zamzani, A. 2007. Agresivitas Siswa SMK DKI Jakarta. Jurnal Pendidikan dan Kebudayaan. No. 069 